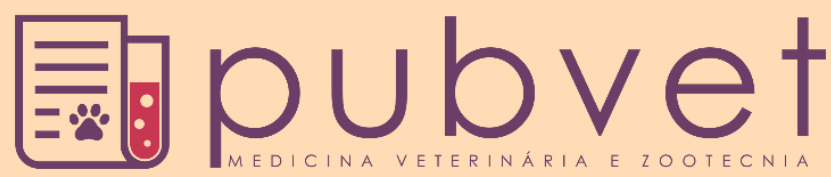

https://doi.org/10.31533/pubvet.v13n1 1a441.1-9

\title{
Produção, qualidade e utilização de silagens de capins tropicais na dieta de ruminantes
}

\author{
Antonio Leandro Chaves Gurgel ${ }^{* \bullet}$, Francisco Carlos Camargo ${ }^{2} \bullet$, Alexandre Menezes Dias ${ }^{2} \bullet$, Juliana $^{\circ}$ \\ Caroline Santos Santana ${ }^{2} \theta$, Carolina Marques $\operatorname{Costa}^{10}$, Ana Beatriz Graciano da $\operatorname{Costa}^{2}{ }^{\circ}$, Manoel \\ Gustavo Paranhos da Silva ${ }^{\circ}$, Wyverson Kim Rocha Machado ${ }^{\circ}{ }^{\circ}$, Patrick Bezerra Fernandes ${ }^{1 \bullet}$ \\ ${ }^{I}$ Aluno do Curso de doutorado em Ciência Animal - Universidade Federal de Mato Grosso do Sul \\ ${ }^{2}$ Aluno do Curso de Mestrado em Ciência Animal - Universidade Federal de Mato Grosso do Sul \\ ${ }^{3}$ Professor do Programa de Pós-Graduação em Ciência Animal - Universidade Federal de Mato Grosso do Sul \\ Autor para correspondência, E-mail: antonioleandro09@gmail.com
}

Resumo. O Brasil possui diversas espécies de capins tropicais que podem ser ensiladas. Esses capins apresentam alto potencial de produção de forragem. Todavia, a maior produção dessas gramíneas ocorre nos períodos de maior disponibilidade de fatores abióticos, o que promove à estacionalidade na produção forrageira, sendo necessário o uso de tecnologias de conservação de forragens para manter alimentos de maior qualidade em tempos de escassez. A ensilagem de capins tropicais no Brasil tem sido limitada por fatores operacionais e por questões inerentes à própria planta, pois, invariavelmente essas plantas apresentam baixos teores de matéria seca e de carboidratos solúveis, além de uma alta capacidade tamponante no momento ideal do corte. Para contornar esses problemas, temse utilizado alguns aditivos com resultados bem interessantes; porém, esta prática pode onerar ainda mais o processo produtivo. Portanto, pretende-se com esta revisão, discutir os principais entraves da produção de silagens a partir de capins tropicais, os fatores que podem alterar a qualidade da silagem e as implicações ao inserir esse tipo de volumoso na dieta de ruminantes.

Palavras-chave: Brachiaria brizantha, forragem conservada, Panicum maximum, Pennisetum purpureum, silagem de gramínea

\section{Production, quality and use of tropical grass silage in the ruminant diet}

Abstract. Brazil has several species of tropical grass that can be ensiled, these grasses have high forage production potential. However, the largest production of these grasses occurs during periods of greater availability of abiotic factors, which promotes seasonality in forage production, requiring the use of forage conservation technologies to maintain higher quality food in times of scarcity. Tropical grass silage in Brazil has been limited by operational factors and by the plant itself, as these plants invariably have low dry matter and soluble carbohydrate contents, as well as a high buffering capacity at the ideal time for cutting. To circumvent these problems some additives have been used with very interesting results, but this practice can further burden the production process. Therefore, the aim of this review is to discuss the main barriers to silage production from tropical grasses, the factors that may alter the quality of silage and the implications of inserting this type of roughage into the ruminant diet.

Keywords: Brachiaria brizantha, grass silage, Panicum maximum, Pennisetum purpureum, pickled forage 


\section{Producción, calidad y utilización de ensilajes de gramíneas tropicales en la dieta de rumiantes}

Resumen. Brasil tiene varias especies de pastos tropicales que pueden ensilarse, estos
pastos tienen un alto potencial de producción de forraje. Sin embargo, la mayor producción
de estos pastos ocurre durante períodos de mayor disponibilidad de factores abióticos, lo
que promueve la estacionalidad en la producción de forraje, lo que requiere el uso de
tecnologías de conservación de forraje para mantener alimentos de mayor calidad en
tiempos de escasez. El ensilaje de pastos tropicales en Brasil se ha visto limitado por
factores operativos y los problemas inherentes de la propia planta, porque estas plantas
tienen invariablemente bajos niveles de materia seca y carbohidratos solubles, así como
una alta capacidad de amortiguación en el momento ideal de corte. Para superar estos
problemas, se han utilizado algunos aditivos con resultados muy interesantes, pero esta
práctica puede dejar más caro el proceso de producción. Por lo tanto, el objetivo de esta
revisión es analizar los principales obstáculos para la producción de ensilaje a partir de
hierba tropical, los factores que pueden cambiar la calidad del ensilaje y las implicaciones
de insertar este tipo de forraje en la dieta de los rumiantes.

Palabras clave: Brachiaria brizantha, forrajes conservadas, Panicum maximum, Pennisetum purpureum, ensilaje de gramínea

\section{Introdução}

Estima-se que aproximadamente $47 \%$ da carne e leite mundial de ruminantes vêm de regiões tropicais e subtropicais (FAPRI, 2019). Nessas regiões, os pastos nativos foram substituídos por gramíneas forrageiras de origem africana de metabolismo $\mathrm{C}_{4} \mathrm{com}$ grande potencial em acumular forragem, particularmente às dos gêneros Brachiaria, Panicum e Cynodon (Euclides et al., 2018a; Euclides et al., 2018b; Euclides et al., 2019; Pontes et al., 2016). Essas plantas forrageiras têm sido estudadas intensivamente nas últimas décadas, apresentando elevada produção por unidade de área e tem reduzido o custo de produção (Euclides et al., 2018b), esses fatores são responsáveis por tornar a produção de ruminantes brasileira competitiva em nível mundial. Entretanto, a maior produção dessas gramíneas ocorre nos períodos de maior disponibilidade de fatores abióticos (luz, temperatura e precipitação), o que promove à estacionalidade na produção forrageira (Gurgel et al., 2017), sendo necessário o uso de tecnologias de conservação de forragens para manter alimentos de maior qualidade em tempos de escassez. Entre as soluções utilizadas para contornar essa problemática, ressalta-se a confecção de silagens - uma prática relativamente simples e acessível para os criadores.

O uso da silagem de gramíneas forrageiras tropicais tem se tornado uma prática cada vez mais comum na alimentação de ruminantes (Epifanio et al., 2014; Perim et al., 2014; Rêgo et al., 2010). No entanto, essas plantas apresentam características que podem influenciar a qualidade da silagem. Esta revisão tem como objetivo discutir os principais entraves da produção de silagens a partir de capins tropicais, os fatores que podem alterar a qualidade da silagem e as implicações ao inserir esse tipo de volumoso na dieta de ruminantes.

\section{Produção de silagem de capins tropicais}

A história da preservação de alimentos é tão antiga quanto à história do homem, começando no Egito antigo, cerca de 1000-1500 anos antes de Cristo (Wilkinson \& Muck, 2019). No Brasil, a prática da ensilagem teve seu início no final do século 19. No entanto, foi a partir de 1920, quando a importação de máquinas e tratores criou força no país à técnica se difundiu ao longo dos anos, inicialmente com milho e posteriormente, com o sorgo e o capim-elefante na década de 60 (Daniel et al., 2019).

O princípio básico da silagem é a fermentação de açúcares por bactérias, com produção de ácidos orgânicos e consequente redução do pH da massa ensilada. Embora o processo pareça bastante simples, com o uso de carboidratos solúveis próprios da forragem ou adicionados, fermentados por bactérias epífitas ou adicionadas (Wilkinson \& Davies, 2013), os possíveis caminhos da fermentação tornam o 
processo complexo. Portanto, para a obtenção de um produto de qualidade é necessário cumprir várias etapas como: colheita e trituração da forrageira, transporte da forrageira picada até o silo, descarga e a distribuição da massa a ser ensilada no silo, compactação e a vedação do silo. Além do cuidado com a contaminação desta massa durante estes procedimentos principalmente no ambiente do silo durante a descarga, distribuição e compactação.

Para maiores detalhamentos acerca dos processos produtivos, fermentativos e tecnológicos da silagem recomenda-se leitura de outras bases literárias (Bueno et al., 2018; Daniel et al., 2019; Jobim et al., 2007; Wilkinson \& Davies, 2013; Wilkinson \& Muck, 2019), pois essa revisão tem como objetivo discutir os principais entraves da produção de silagens a partir de capins tropicais, os fatores que podem alterar a qualidade da silagem e as implicações ao inserir esse tipo de volumoso na dieta de ruminantes, portanto não dará enfoque para cada etapa do processo produtivo e fermentativo.

O Brasil possui diversas espécies de capins tropicais que podem ser ensiladas as quais: Pennisetum purpureum (Capim-Elefante), Panicum maximum (Mombaça, Tanzânia, Massai, Quênia, Zuri, Quênia, Tamani), Brachiaria brizantha (Marandu, Piatã, Xaraés, Paiaguás, Ipyporã), Brachiaria decumbens (Basilisk) e as cultivares do gênero Cynodon (Tifton e Coastcross) (Ferraz \& Felício, 2010). Esses capins apresentam alto potencial de produção de forragem (Euclides et al., 2018a; Euclides et al., 2019; Pontes et al., 2016). Entretanto, para atingir essa alta produção são necessários vários cortes, principalmente durante o período chuvoso, o que pode limitar a logística do processo de ensilagem e a realização da pré-secagem, etapa essencial na confecção da silagem de capins tropicais. Desse modo, na pratica, os produtores tem adotado outros métodos de conservação como o diferimento para cultivares de Brachiaria (Santos et al., 2014), feno e produção de silagens pré-secadas para cultivares de Cynodon. No caso do capim-elefante, a principal forma de utilização é por meio do uso de campineiras, com tudo, esse é o capim tropical mais utilizado para produção de silagem (Monteiro et al., 2011).

Daniel et al. (2011) realizaram uma simulação dos custos de produção de diferentes silagens. Os autores adotaram parâmetros relativos à composição nutricional e características produtivas das plantas a serem ensiladas e, para a composição do custo total de cada silagem foi considerado as etapas de cultivo, colheita, ensilagem e oferta para os animais, além das perdas de cada fase (Tabela 1).

Tabela 1. Variáveis produtivas, nutricionais e custo de produção de silagens de diferentes forrageiras

\begin{tabular}{|c|c|c|c|c|}
\hline Variáveis & Milho & Sorgo & Cana & Tanzânia \\
\hline & \multicolumn{4}{|c|}{-------Produção/qualidade------- } \\
\hline Produtividade (t MV/ha) & 41,0 & 44,0 & 84,0 & 100,0 \\
\hline Produtividade (t MS/ha) & 13,0 & 13,2 & 25,2 & 20,0 \\
\hline MS (\%) & 32,0 & 32,0 & 30,0 & 20,0 \\
\hline NDT $(\%)$ & 65,0 & 60,0 & 58,0 & 56,0 \\
\hline \multirow[t]{2}{*}{$\mathrm{PB}(\%)$} & 8,7 & 9,4 & 3,5 & 7,8 \\
\hline & \multicolumn{4}{|c|}{-------Custo------- } \\
\hline Insumos & 2010,0 & 1745,7 & 2980,9 & 3082,9 \\
\hline Investimentos & 171,9 & 171,9 & 169,8 & 694,7 \\
\hline Preparo do solo & 225,4 & 225,4 & 164,7 & 59,8 \\
\hline Plantio e tratos culturais & 145,7 & 145,7 & 767,8 & 86,1 \\
\hline Colheita e ensilagem & 842,8 & 928,5 & 1238,5 & 1102,3 \\
\hline Descarga e distribuição & 661,6 & 661,6 & 1040,4 & 1122,3 \\
\hline \multirow[t]{2}{*}{ Aditivação } & - & - & 13,2 & - \\
\hline & \multicolumn{4}{|c|}{-------Total------- } \\
\hline $\mathrm{R} \$ / \mathrm{ha}$ & 4057,4 & 3878,8 & 3790,8 & 4402,3 \\
\hline $\mathrm{R} \$ / \mathrm{t} \mathrm{MV}$ & 99,5 & 88,2 & 61,4 & 67,7 \\
\hline $\mathrm{R} \$ / \mathrm{t} \mathrm{MS}$ & 310,9 & 293,8 & 204,8 & 338,6 \\
\hline
\end{tabular}

Adaptado Daniel et al. (2011). MS: matéria seca; PB: proteína bruta; NDT: nutrientes digestíveis totais.

Conforme apresentado na tabela 1, a silagem de capim-Tanzânia, apesar de gerar baixo custo por tonelada de massa verde, decorrente da grande produção de forragem, foi a que apresentou os custos 
mais elevados. Esse capim apresenta baixo teor de matéria seca e quando se equaciona o custo em razão da matéria seca, este se torna mais oneroso do que as opções de culturas anuais. Os autores ainda alertam para o fato de esses capins tropicais apresentarem baixo valor nutritivo se comparado ao milho, aliado as perdas totais estimadas superiores a $40 \%$ da MS em silos de grande porte, constituindo-se numa fonte de nutrientes com custo elevado. O conteúdo de nutrientes da ração animal é baseado no teor de MS, portanto todo o custo de produção deve ser baseado pelo preço do $\mathrm{kg}$ da matéria seca.

\section{Qualidade de silagem de capins tropicais}

A qualidade da forragem é uma expressão utilizada como referência ao valor nutritivo da massa de forragem em interação com o consumo efetuado pelo animal e com o potencial de desempenho do animal (Jobim et al., 2007). Desse modo, a qualidade da silagem de capins tropicais vai variar em função de diversos fatores, pois esses capins apresentam algumas características que interferem a qualidade da silagem e pode sofrer alterações conforme o processo da ensilagem.

Além dos fatores ligados a tecnologia de ensilagem, outros aspectos relacionados à própria planta são importantes para a qualidade da silagem, com destaque para teor de matéria seca, a concentração de açúcares solúveis em água e a capacidade tamponante que determinam em grande parte a qualidade de fermentação no silo (Jobim et al., 2007). Quando uma planta forrageira apresenta esses três fatores adequados é então classificada como de alta capacidade de fermentação (Bolsen, 1995; Brondani et al., 2000; Woolford \& Pahlow, 1998), caso contrário tem baixa capacidade de fermentação e cuidados especiais devem ser tomados para que a silagem tenha boa conservação. Na tabela 2 são apresentadas as capacidades de fermentação de algumas plantas forrageiras entre elas os capins tropicais conforme descrito em (Bolsen, 1995; Brondani et al., 2000; Woolford \& Pahlow, 1998).

Tabela 2. Capacidade de fermentação de plantas forrageiras.

\begin{tabular}{lcccc}
\hline Forrageira & Teor de MS & Carboidratos Solúveis & Capacidade Tamponante & Capacidade de fermentação \\
\hline Milho & Bom & Alto & Baixa & Ótima \\
Sorgo & Bom & Bom & Baixa & Boa \\
Capins & Baixo & Médio & Alta & Média \\
Leguminosas & Baixo & Baixo & Alta & Ruim \\
\hline
\end{tabular}

Nota-se que os capins tropicais apresentam baixos teores de matéria seca e de carboidratos solúveis, além de uma alta capacidade tamponante no momento ideal do corte. Caso aumente a idade de corte para elevar os teores de matéria seca ocorrerá, inevitavelmente uma redução nos teores de carboidratos solúveis, que aliado com uma maior dificuldade na compactação do silo (Silva et al., 2015), aumentara os riscos de a fermentação não se completar de forma adequada. Diante desse dilema algumas medidas devem ser tomadas, como a técnica de pré-secagem, que se tem mostrado eficiente para elevar o teor de matéria seca (Fluck et al., 2017). Além disso, elevados teores de umidade e a anaerobiose potencializa a atividade clostridiana, o que pode levar a fermentações indesejáveis aumentando significativamente as perdas em qualidade nutricional devido à proteólise (Liu et al., 2011; Xie et al., 2012).

Além da pré-secagem, os produtores podem utilizar aditivos sequestrantes de umidade com o intuito de se elevar a matéria seca da massa ensilada. O milho desintegrado com palha e sabugo, polpa cítrica, raspa de batata e mandioca, farelo de trigo, grão de milho moído, rolão de milho (Perim et al., 2014; Rezende et al., 2008), glicerina (Tonin et al., 2018), além de muitos outros subprodutos como casca de café, bagaço de laranja in natura, restos da cultura da soja (Barcelos et al., 2018; Dias et al., 2014; Ítavo et al., 2000; Lopes et al., 2007; Siqueira, 2009) são aditivos que elevam os teores de matéria seca.

Alguns aditivos que têm a capacidade de sequestrar umidade também são ricos em carboidratos que supostamente poderia elevar os substratos para a fermentação lática no interior do silo por meio do fornecimento de carboidratos solúveis. No entanto, a maioria desses aditivos tem como principal carboidrato o amido, que não constitui um adequado substrato para a fermentação dentro do silo, uma vez que esse polissacarídeo não é fermentado pelas bactérias normalmente encontradas nas plantas forrageiras. Para fornecer um substrato para a população bacteriana e consequente aumento e aceleração da atividade fermentativa tem-se utilizado outros aditivos como melaço e polpa cítrica na confecção de silagens de capins tropicais (Rezende et al., 2008). 
Existem várias formas de se avaliar a qualidade de um alimento conservado (olfato, análises químicas, físicas e microbiológicas e desempenho dos animais). Na tabela 3 estão apresentados alguns parâmetros qualitativos da silagem de diferentes plantas.

Tabela 3. Parâmetros qualitativos de silagens de diferentes plantas

\begin{tabular}{lccccccc}
\hline Forragem & MS (\%) & PE (kg/t MV) & $\mathrm{pH}$ & PB (\%) & NDT (\%) & DIVMS (\%) & Autor \\
\hline Elefante & 16,4 & - & 4,2 & 8,4 & 59,6 & 49,8 & Tonin et al. (2018) \\
Elefante & 23,7 & 24,9 & 3,9 & 7,0 & 56,0 & - & Rezende et al. (2008) \\
Elefante $^{1}$ & 26,9 & 1,83 & 3,9 & 7,7 & 66,0 & - & Rezende et al. (2008) \\
Marandu & 24,7 & - & - & 8,9 & - & 65,7 & Bergamaschine et al. (2006) \\
Tanzania & 27,7 & 46,1 & 4,0 & 5,7 & 41,1 & 43,4 & Melo et al. (2016) \\
Milho & 32,5 & - & 3,8 & 7,6 & 66,3 & 65.09 & Zardin et al. (2017) \\
\hline
\end{tabular}

${ }^{1}$ capim-elefante aditivado com 7\% de polpa cítrica; MS: matéria seca; PE: perdas por efluentes; PB: proteína bruta; NDT: nutrientes digestíveis totais; DIVMS: digestibilidade in vitro da matéria seca.

Observa-se que teor de matéria seca nas silagens dos capins tropicais está bem abaixo dos valores tidos como ideal para um correto processo fermentativo. O teor ideal de MS varia de $30 \%$ a 35\% da matéria natural (Rezende et al., 2008), sendo que apenas a silagem de milho está dentro dessa faixa. A utilização de polpa cítrica aumentou significativamente os teores de MS da silagem de capim-elefante, o que reduziu drasticamente as perdas por efluentes. A utilização do aditivo também elevou os teores de proteína bruta e digestibilidade in vitro da silagem (Rezende et al., 2008). Vale ressaltar que independentemente do uso ou não de aditivos, os capins tropicais sempre originaram silagens de menor qualidade se comparada com a silagem de milho, o que torna a dieta mais cara, devido ao elevado uso de concentrado necessário para atender as exigências do animal, como será discutido posteriormente.

Em um estudo metanalitico, Zardin et al. (2017) analisaram a composição bromatológica de silagens de milho, estudadas ou utilizadas em dietas para ruminantes, em condições experimentais brasileiras. Foram utilizados artigos publicados entre janeiro de 1994 e dezembro de 2014, totalizando 203 artigos científicos com 647 tratamentos, envolvendo a análise de 1.701 silos. Algumas variáveis foram intensamente avaliadas, como o teor de proteína bruta, matéria seca, e a porção fibrosa (FDN, FDA e lignina). Os autores alertam para a importância superestimada que as pesquisas dão ao teor de proteína bruta, pois esse componente tem pouco efeito sobre a qualidade da silagem, visto que representa menos de $10 \%$ do total de constituintes da silagem e, quando o processamento da silagem é realizado de acordo com procedimentos básicos estabelecidos, o teor de proteína bruta não afeta significativamente a qualidade. No entanto, algumas variáveis importantes para avaliar a qualidade da silagem como: ácido láctico, $\mathrm{pH}$ e digestibilidade foram determinadas respectivamente, 21,2; 33,4 e 20,4\%, valor considerado baixo dada a importância desses componentes na avaliação da silagem. Os autores concluíram que existe uma escassez de informações sobre os teores de ácidos orgânicos, uma vez que a maioria dos estudos científicos que produzem silagem de milho no Brasil não relata composição química completa.

Cabe salientar que a silagem de milho é a mais produzida, estudada e utilizada, e mesmo assim, existem informações essenciais acerca da qualidade da silagem de milho que estão sendo negligenciadas nas pesquisas. Portanto, existem poucas informações para gerar qualquer conclusão sobre a qualidade das silagens de capins tropicais, tendo em vista o número baixo de pesquisas com a silagem dessas plantas comparativamente a silagem de milho.

\section{Utilização da silagem de capins tropicais}

Para demonstrar a importância da qualidade da silagem e sua inter-relação com o atendimento das exigências dos animais, no tópico de utilização de silagens de capins tropicais, realizaremos uma simulação com duas categorias de animais recebendo dietas contendo diferentes silagens como fonte de volumoso. Essa simulação não pretende indicar uma silagem ou opções de suplementos, mas demonstrar o impacto do volumoso na dieta total dos animais.

Para a simulação foram utilizadas as informações nutricionais da silagem de milho (Zardin et al., 2017), capim Elefante (Rezende et al., 2008) e da silagem de capim Tanzânia (Melo et al., 2016), que estão contidas na tabela 3. As exigências para a vaca de leite foram calculadas de acordo com as 
recomendações do NRC (1989) para um animal no meio da lactação com $600 \mathrm{~kg}$ de peso vivo e uma produção de leite de $20 \mathrm{~kg} /$ dia recebendo uma dieta com $40 \%$ de concentrado e $60 \%$ de volumoso. No caso do bovino de corte, optou-se por calcular as exigência para crescimento e terminação de um zebuíno, macho castrado em confinamento com peso vivo inicial de $350 \mathrm{~kg}$ e $500 \mathrm{~kg}$ de peso vivo final, objetivando-se um ganho médio diário de 1,5 kg (Valadares Filho et al., 2016), optou-se por uma razão volumoso:concentrado de 40:60.

$\mathrm{Na}$ tabela 4, encontram-se os resultados referentes aos cálculos das exigências e a contribuição de das diferentes silagens para o atendimento das exigências de diferentes categorias. A fonte de volumoso atendeu em média 24,0\% das exigências de PB para o bovino de corte, variando de 23,0\% para a silagem de capim Tanzânia e 25,4\% para a silagem de milho. A silagem de milho como fonte de volumoso atendeu cerca de $28,0 \%$ das exigências de PB da vaca de leite, ao passo que a silagem de capim Tanzânia atende apenas, 20,7\%. Essa maior amplitude observada para a vaca de leite é resultado da maior participação do volumoso na dieta. Mesmo com essas oscilações, verifica-se que, para bovinos a fonte de volumoso exerceu pouca influência para o atendimento da exigência de $\mathrm{PB}$, pois bastaria formular um concentrado com aproximadamente $25 \%$ de PB para atender as exigências em todas as dietas. Portanto, a PB não é um bom parâmetro para comparar a qualidade da silagem para os ruminantes (Zardin et al., 2017).

Tabela 4. Simulação de exigências para vacas leiteiras e bovinos de corte com diferentes silagens

\begin{tabular}{|c|c|c|c|c|c|c|}
\hline \multicolumn{4}{|c|}{ Vaca de leite } & \multicolumn{3}{|c|}{ Bovino de corte } \\
\hline & CMS & NDT & $\mathrm{PB}$ & CMS & NDT & PB \\
\hline \multicolumn{7}{|c|}{--------------Milho--------------- } \\
\hline Exigência(kg/dia) & 18,0 & 12,9 & 2,9 & 9,5 & 7,2 & 1,1 \\
\hline Silagem $^{1}(\mathrm{~kg} / \mathrm{dia})$ & 10,8 & 7,1 & 0,8 & 3,8 & 2,5 & 0,28 \\
\hline Déficit (kg/dia) & 7,2 & 5,8 & 2,1 & 5,7 & 4,7 & 0,82 \\
\hline \multicolumn{7}{|c|}{--------------Capim-elefante-------------- } \\
\hline Exigência (kg/dia) & 18 & 12,9 & 2,9 & 9,5 & 7,2 & 1,1 \\
\hline Silagem $^{1}(\mathrm{~kg} / \mathrm{dia})$ & 10,8 & 6,0 & 0,7 & 3,8 & 2,1 & 0,26 \\
\hline Déficit (kg/dia) & 7,2 & 6,9 & 2,2 & 5,7 & 5,1 & 0,83 \\
\hline \multicolumn{7}{|c|}{--------------Capim-tanzânia-------------- } \\
\hline Exigência (kg/dia) & 18 & 12,9 & 2,9 & 9,5 & 7,2 & 1,1 \\
\hline Silagem $^{1}(\mathrm{~kg} / \mathrm{dia})$ & 10,8 & 4,4 & 0,6 & 3,8 & 1,6 & 0,22 \\
\hline Déficit (kg/dia) & 7,2 & 8,5 & 2,3 & 5,7 & 5,6 & 0,88 \\
\hline
\end{tabular}

${ }^{1}$ contribuição da silagem dentro da dieta total. CMS: consumo matéria de seca; PB: proteína bruta; NDT: nutrientes digestíveis totais.

No entanto, o tipo de silagem teve bastante influência no atendimento das exigências de NDT, independentemente da categoria. Para o bovino de corte, a silagem de milho atendeu 35\% da exigência, já para a vaca de leite esse valor foi de 55,0\%. Ao passo que a silagem de capim Tanzânia atendeu apenas $22,2 \%$ das exigências de NDT do bovino de corte e de 34,1 da vaca de leite. Com isso, caso o produtor opte por usar a silagem de milho para completar a dieta dos animais, teria que formular um suplemento contendo $80 \%$ de NDT para a vaca de leite e $82 \%$ para o bovino de corte, para atender as exigências de NDT.

Caso o produtor queira usar a silagem de capim Tanzânia, seria necessário formular uma dieta com 98\% de NDT para o bovino de corte e com $118 \%$ para a vaca de leite, ou seja, em ambos os casos o nutricionista precisaria usar ingredientes para aumentar a densidade energética da dieta e/ou alterar a razão volumoso:concentrado, caso contrário não atenderia as exigências, o que vai acarretar em aumentos nos custos de produção. O capim-elefante pode ser uma alternativa, mesmo assim fica muito atrás da silagem de milho. Portanto, a silagem de milho torna-se muito favorável, pois a diluição de seus custos de produção (Tabela 1), associada a sua melhor participação na dieta diminui a dependência por concentrado e pode possibilitar menores custos da dieta e lucros por animal superiores aos obtidos em dieta a base de silagem de capins tropicais. 


\section{Considerações finais}

A ensilagem de capins tropicais no Brasil tem sido limitada por fatores operacionais uma vez que a maioria dos produtores não tem equipamentos para a realização de diversos cortes ao longo do ano. A qualidade fermentativa também tem limitado a produção de silagem de capins tropicais, pois invariavelmente essas plantas apresentam baixos teores de matéria seca e de carboidratos solúveis, além de uma alta capacidade tamponante no momento ideal do corte. Para contornar esses problemas tem-se utilizado alguns aditivos com resultados bem interessantes; porém, podem onerar ainda mais o processo produtivo. Por fim, as silagens mais tradicionais como a de milho, apresentam vantagens em relação às obtidas a partir de capins tropicais (esse tipo de silagem deve ser feita em casos específicos), pois existe outras opções para o melhor aproveitamento dessas plantas.

\section{Referências bibliográficas}

Barcelos, A. F., de Carvalho, J. R. R., Tavares, V. B. \& Gonçalves, C. C. M. (2018). Valor nutritivo e características fermentativas da silagem de capim-elefante com diferentes proporções de casca de café. Ciência Animal Brasileira, 191-12.

Bergamaschine, A. F., Passpler, M., Veriano Filho, W. V., Isepon, O. J. \& Corrêa, L. A. (2006). Qualidade e valor nutritivo de silagens de capim-marandu (B. brizantha cv. Marandu) produzidas com aditivos ou forragem emurchecida. Revista Brasileira de Zootecnia, 351454-1462.

Bolsen, K. K. (1995). Silage: basic principles. Forages, 5163-176.

Brondani, I. L., Alves Filho, D. C., Bernardes, R. A. C. \& Restle, J. (2000). Silagem de alta qualidade para bovinos. In j. Restle (Ed.), Eficiência na produção de bovinos de corte. Santa Maria: Universidade Federal de Santa Maria (Vol. 1, pp. 185-204). Santa Maria, Rio Grande do Sul: Universidade Federal de Santa Maria.

Bueno, A. V. L., Jobim, C. C., Rossi, R. M., Gritti, V. C., Leão, G. F. M. \& Tres, T. T. (2018). Wilting whole crop black oat with glyphosate for ensiling: effects on nutritive, fermentative, and aerobic stability characteristics. Revista Brasileira de Zootecnia, 471-7.

Daniel, J. L. P., Bernardes, T. F., Jobim, C. C., Schmidt, P. \& Nussio, L. G. (2019). Production and utilization of silages in tropical areas with focus on Brazil. Grass and Forage Science, 74(2):188200.

Daniel, J. L. P., Zopollatto, M. \& Nussio, L. G. (2011). A escolha do volumoso suplementar na dieta de ruminantes. Revista Brasileira de Zootecnia, 40261-269.

Dias, A. M., Ítavo, L. C., Ítavo, C. C. B., Blan, L. R., Gomes, E. N., Soares, C. M., . . Coelho, E. M. (2014). Ureia e glicerina bruta como aditivos na ensilagem de cana-de-açúcar. Arquivo Brasileiro de Medicina Veterinaria e Zootecnia, 661874-1882.

Epifanio, P. S., Costa, K. A. P., Severiano, E. C., Cruvinel, W. S., Bento, J. C. \& Perim, R. C. (2014). Fermentative and bromatological characteristics of Piata palisadegrass ensiled with levels of meals from biodiesel industry. Semina: Ciências Agrárias, 35(1):491-504. doi: https://dix.doi.org/10.5433/1679-0359.2014v35n1p491.

Euclides, V. P. B., Carpejani, G. C., Montagner, D. B., Nascimento Junior, D., Barbosa, R. A. \& Difante, G. S. (2018a). Maintaining post-grazing sward height of Panicum maximum (cv. Mombaça) at 50 $\mathrm{cm}$ led to higher animal performance compared with post-grazing height of $30 \mathrm{~cm}$. Grass and Forage Science, 73(1):174-182.

Euclides, V. P. B., Costa, F. P., Euclides Filho, K., Montagner, D. B. \& Figueiredo, G. R. (2018b). Biological and economic performance of animal genetic groups under different diets. Bioscience Journal, 34683-692.

Euclides, V. P. B., Montagner, D. B., Macedo, M. C. M., Araújo, A. R., Difante, G. S. \& Barbosa, R. A. (2019). Grazing intensity affects forage accumulation and persistence of Marandu palisadegrass in the Brazilian savannah. Grass and Forage Science, 74(3):450-462.

FAPRI. (2019). Food and Agricultural Policy Research Institute. Food and Agricultural Policy Research Institute, from http://www.fapri.iastate.edu/tools/outlook.aspx 
Ferraz, J. B. S. \& Felício, P. E. (2010). Production systems - An example from Brazil. Meat Science, 84(2):238-243. doi: http://dx.doi.org/10.1016/j.meatsci.2009.06.006.

Fluck, A. C., Parzianello, R. R., Maeda, E. M., Piran Filho, F. A., Costa, O. A. D. \& Simionatto, M. (2017). Caracterização química da silagem de rama de cultivares de mandioca com ou sem présecagem. Boletim de Indústria Animal, 74(3):176-181.

Gurgel, A. L. C., Difante, G. S., Emerenciano Neto, J. V., Souza, J. S., Veras, E. L. L., Costa, A. B. G., ... Roberto, F. F. S. (2017). Estrutura do pasto e desempenho de ovinos em capim-massai na época seca em resposta ao manejo do período das águas. Boletim de Indústria Animal, 74(2):86-95.

Ítavo, L. C. V., Santos, G. T., Jobim, C. C., Voltolini, T. V., Bortolassi, J. R. \& Ferreira, C. C. B. (2000). Conservation of fresh orange peel by ensilage process using additives. Aditivos na Conservação do Bagaço de Laranja in natura na Forma de Silagem 1, 29(5):1474-1484.

Jobim, C. C., Nussio, L. G., Reis, R. A. \& Schmidt, P. (2007). Avanços metodológicos na avaliação da qualidade da forragem conservada. Revista Brasileira de Zootecnia, 36(Especial):101-119. doi: http://dx.doi.org/10.1590/S1516-35982007001000013.

Liu, Q., Zhang, J., Shi, S. \& Sun, Q. (2011). The effects of wilting and storage temperatures on the fermentation quality and aerobic stability of stylo silage. Animal Science Journal, 82(4):549-553.

Lopes, J., Evangelista, A. R. \& Rocha, G. P. (2007). Valor nutricional da silagem de cana-de-açúcar acrescida de uréia e aditivos absorventes de umidade. Revista Brasileira de Zootecnia, 36(4):11551161.

Melo, M. J. A. F., Backes, A. A., Fagundes, J. L., Melo, M. T., Silva, G. P. \& Freire, A. P. L. (2016). Características fermentativas e composição química da silagem de capim tanzânia com aditivo. Boletim de Indústria Animal, 73(3):189-197.

Monteiro, I. J. G., Abreu, J. G., Silva Cabral, L., Ribeiro, M. D. \& dos Reis, R. H. P. (2011). Silagem de capim-elefante aditivada com produtos alternativos. Acta Scientiarum. Animal Sciences, 33(4):347-352.

NRC. (1989). Nutrient Requirements of Dairy Cattle (7th rev. ed.). Washington: Natl. Acad. Press, Washington, DC.

Perim, R. C., Costa, K. A. d. P., Epifanio, P. S., Teixeira, D. A. A., Fernandes, P. B. \& Santos Júnior, D. R. s. (2014). Protein and carbohydrate fractionation of Piata palisadegrass ensiled with energetic meals. Acta Scientiarum. Animal Sciences, 36(2):193-200.

Pontes, L. S., Giostri, A. F., Baldissera, T. C., Barro, R. S., Stafin, G., Porfírio-da-Silva, V., . . Carvalho, P. C. F. (2016). Interactive effects of trees and nitrogen supply on the agronomic characteristics of warm-climate grasses. Agronomy Journal, 108(4):1531-1541.

Rêgo, M. M. T., Neiva, J. N. M., Rêgo, A. C., Cândido, M. J. D., Clementino, R. H. \& Restle, J. (2010). Nutritional evaluation of elephant-grass silages with byproduct of annato. Revista Brasileira de Zootecnia, 39(10):2281-2287. doi: 10.1590/S1516-35982010001000026

Rezende, A. V., Gastaldello Junior, A. L., Valeriano, A. R., Casali, A. O., Medeiros, L. T. \& Rodrigues, R. (2008). Uso de diferentes aditivos em silagem de capim-elefante. Ciência e Agrotecnologia, 32(1):281-287. doi: http://dx.doi.org/10.1590/S1413-70542008000100040.

Santos, M. E. R., Sant'Anna, M. R., Gouvêia, S. C., Gomes, V. M., Fonseca, D. M. \& Santana, S. S. (2014). Contribuição de perfilhos aéreos e basais na dinâmica de produção de forragem do capimbraquiária após o pastejo diferido. Bioscience Journal, 30(3):424- 430. .

Silva, M. S. J., Jobim, C. C., Poppi, E. C., Tres, T. T. \& Osmari, M. P. (2015). Production technology and quality of corn silage for feeding dairy cattle in Southern Brazil. Revista Brasileira de Zootecnia, 44(9):303-313. doi: http://dx.doi.org/10.1590/S1806-92902015000900001.

Siqueira, G. R. (2009). Aditivos na silagem de cana-de-açúcar "in natura" ou queimada. Jaboticabal.

Tonin, T. J., Viégas, J., Silveira, A. M., Moro, G., Pereira, S. N., Dotto, L. R., . . Schumacher, L. L. (2018). Substituição do milho moído pela glicerina como aditivo em silagem de capim elefante. Boletim da Indústria Animal, 75. 
Valadares Filho, S. C., Costa e Silva, L. F., Gionbelli, M. P., Rotta, P. P., Marcondes, M. I., Chizzotti, M. L. \& Prados, L. F. (2016). Exigências nutricionais de zebuínos puros e cruzado - BR-Corte (Vol. 1). Viçosa, Minas Gerais: Universidade Federal de Viçosa.

Wilkinson, J. M. \& Davies, D. R. (2013). The aerobic stability of silage: key findings and recent developments. Grass and Forage Science, 68(1):1-19.

Wilkinson, J. M. \& Muck, R. E. (2019). Ensiling in 2050: Some challenges and opportunities. Grass and Forage Science, 74178-187.

Woolford, M. K. \& Pahlow, G. (1998). The silage fermentation. New York: Springer.

Xie, Z. L., Zhang, T. F., Chen, X. Z., Li, G. D. \& Zhang, J. G. (2012). Effects of maturity stages on the nutritive composition and silage quality of whole crop wheat. Asian-Australasian Journal of Animal Sciences, 25(10):1374-1380.

Zardin, P. B., Velho, J. P., Jobim, C. C., Alessio, D. R. M., Haygert-Velho, I. M. P., Conceição, G. M. \& Almeida, P. S. G. (2017). Chemical composition of corn silage produced by scientific studies in Brazil-A meta-analysis. Semina: Ciências Agrárias, 38(1):503-511.

Recebido: 30 de setembro, 2019.

Aprovado: 22 de outubro, 2019.

Publicado: 8 de novembro, 2019.

Licenciamento: Este artigo é publicado na modalidade acesso aberto sob a licença Creative Commons Atribuição 4.0 (CC-BY 4.0), a qual permite uso irrestrito, distribuição, reprodução em qualquer meio, desde que o autor e a fonte sejam devidamente creditados. 